\title{
Diamond like carbon coatings for potential application in biological implants-a review
}

\author{
C.A. Love*, R.B. Cook, T.J. Harvey, P.A. Dearnley, R.J.K. Wood \\ National Centre for Advanced Tribology at Southampton (nCATS), Engineering Sciences, University of Southampton, Highfield, Southampton SO17 1BJ, UK
}

\section{A R T I C L E I N F O}

Article history:

Received 17 November 2011

Received in revised form

29 August 2012

Accepted 11 September 2012

Available online 26 September 2012

Keywords:

Diamond Like

Delamination

\begin{abstract}
A B S T R A C T
Production of wear debris has been linked to the failure of numerous hip implants. With the current focus on increasing the implant longevity, thus wear and corrosion resistance is important. Hard coatings have the potential to reduce the wear and corrosion. Diamond like Carbon (DLC) coatings exhibit properties that could make them viable for implants. This paper critically reviews previously published research into usage of DLC coatings for implants. Overall DLCs seem to be an effective coating for implants but with the variance in results, further testing is required for clarification of use.
\end{abstract}

(c) 2012 Elsevier Ltd. All rights reserved.

\section{Introduction}

With an increase in the number of implants inserted each year $(166,000$ hip and knee replacement surgeries in England and Wales in 2010, compared to 114,497 in 2009 and 109,825 in 2008 [1]), a decrease in the age that patients are considered for the operation, and a population which is living longer; the need for long lasting implants is becoming a larger concern. The current average life span of 15 years for hip implants is not sufficient in a population that may require 30-40 years of service.

Metal on Metal (MoM) bearing surfaces (of joint replacements) produce lower volumes of wear when compared to metal on polymer (MoP) and Ceramic on Polymer (CoP) variants. However, recent medical issues, such as pseudotumour formation [2] linked with metallic debris generation and metal ion release have resulted in MoM joint replacements gaining a negative reputation amongst clinicians. This has favoured the uptake of MoP, CoP and Ceramic on Ceramic $(\mathrm{CoC})$ alternatives. These bearing pairings do have their own risks. In young active individuals the high volume of wear debris created from the polymer bearing surfaces can cause adverse biological reactions, while for ceramic bearings there is always a small risk of catastrophic fracture [3,4].

The purpose of this review is to evaluate the potential benefit of using diamond like carbon (DLC) coated metal components for biological implants, particularly in total hip and total knee replacement devices. DLC coatings offer a hard, wear resistant, inert and low friction surface engineered solution to enhance implant performance. The review takes a critical look at past research in this

\footnotetext{
* Corresponding author.

E-mail address: cerrilove@gmail.com (C.A. Love).
}

sector and highlights reported successes and failures (and the reason behind both), to see where DLC coated metal components need to be improved to make them more viable for use in the human body. The review further considers relevant advances and improvements in DLC coating composition and deposition methods that might be exploited in the next generation of implants.

The mechanical loading and environment which joint replacements are expected to endure are extremely harsh. Implant materials may need to endure high contact pressures (particularly load bearing implants, such as hip replacements), that are both cyclic and unpredictable, while in a severely corrosive solution containing high concentrations of ionic species, as well as organic and biological molecules which are capable of forming complexes with metallic species accelerating the corrosion [5]. In addition, wear debris can cause adverse biological reactions in the body, the material may be rejected by the immune system or the environment may have undesirable effects on material properties. For this reason the materials used in the body are restricted to a few corrosion resistant, biocompatible choices; the most common of which are titanium alloys, surgical grade austenitic stainless steels, cobalt chromium molybdenum alloys, alumina based ceramics and polymers such as ultra-high molecular weight polyethylene (UHMWPE).

At least three previous reviews have been published in the last eleven years on the use of DLC coatings on biomedical implants. Reviews by Dearnaley and Arps [6], Hauert [7] and Cui and Li [8] all show promise in the use of a DLC coatings in in vitro testing. All propose further testing, with Dearnaley and Arps [6] suggesting the time for in vivo testing has arrived, whereas Hauert and Cui and Li suggest further in vitro testing is needed due to variable results. However all these reviews are at least 7 years out of date, with this review aiming to update the study with papers that have been published in the intervening years. 


\section{DLC coatings}

\subsection{Chemistry and structure}

Diamond like Carbon (DLC) is the name given to the broad range of amorphous carbon coatings, with differing ratios of $\mathrm{sp}^{2}$ and $\mathrm{sp}^{3}$ bonded carbon with differing levels of hydrogen. The ratio of these three components can be varied to provide a range of different properties. Coatings can have similar properties to diamond, but with an amorphous matrix of $\mathrm{sp}^{3}$ nodules in a $\mathrm{sp}^{2}$ bonded matrix. $\mathrm{Sp}^{2}$ bonding, typical in graphite, involves a carbon molecule with one double bond to another atom (typically a second carbon atom) and two single bonds to another atom, which leads to planar configuration, whereas $\mathrm{sp}^{3}$ bonded carbon atoms have three single bonds resulting a tetrahedral arrangement. Coating names are often abbreviated to ta-C (tetrahedral amorphous carbon) for coatings with very high (almost exclusively) $\mathrm{sp}^{3}$ content, a-C (amorphous carbon) for coatings with high $\mathrm{sp}^{3}$ content, between 40 and $80 \%$, and a-C:H (amorphous carbon-hydrogenated) for samples with a greater amount of hydrogen, often coupled with an increase in $\mathrm{sp}^{2}$. A ternary phase diagram for DLC formation showing relationship with respect to sp2, sp3 and hydrogen content can be seen in Fig. 1 [9]. The groupings are not definite and the label applied to coating can depend on the author and manufacturer.

Tribological testing has shown that coatings with higher $\mathrm{sp}^{2}$ content (i.e. a-C:H) tend to have a lower coefficient of friction in dry conditions, but a higher wear rate than a coating with a high $\mathrm{sp}^{3}$ content and low hydrogen content (i.e. ta-C) [9].

One of the largest obstacles to the use of DLC coatings is that high level of internal stress are developed during the coating processing, particularly those with high $\mathrm{sp}^{3} / \mathrm{sp}^{2}$ ratios; coatings with a $90 \% \mathrm{sp}^{3}$ content have been reported to have internal compressive stresses close to $10 \mathrm{GPa}$ [10] (see Fig. 2), while coatings of a-C:H containing high amounts of hydrogen and $\mathrm{sp}^{2}$ bonded carbon structures with little to none $\mathrm{sp}^{3}$ structures typically have the lowest internal stress $(<1 \mathrm{GPa})$. Coatings with high internal stress $(>1 \mathrm{GPa}$ ) are prone to delamination leading to catastrophic failure.

\subsection{Production and deposition}

A variety of methods are used to deposit DLC coatings, the most common being variations on CVD (Chemical Vapour Deposition) and

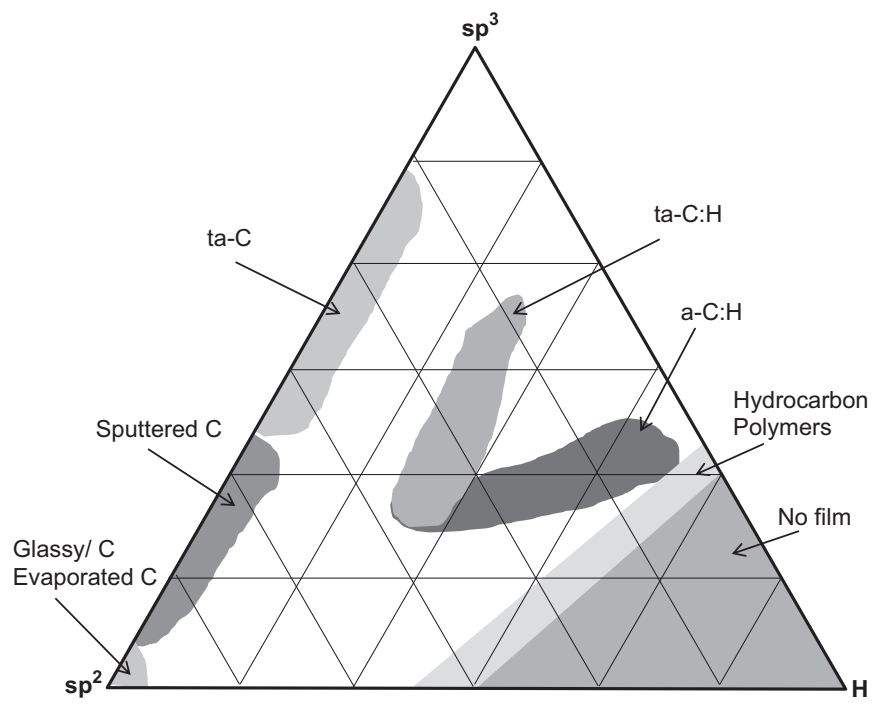

Fig. 1. Ternary phase diagram for DLC formation with respect to $\mathrm{sp}^{2}, \mathrm{sp}^{3}$ and hydrogen content [9].

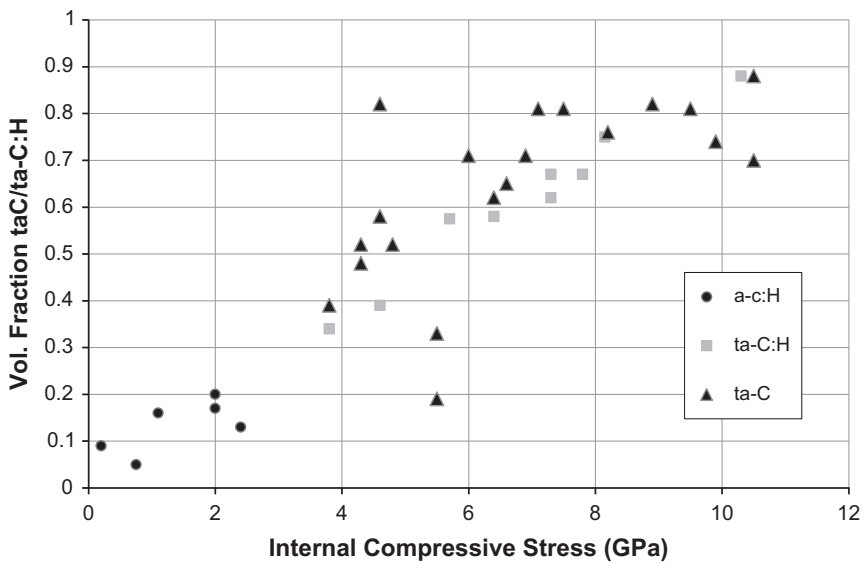

Fig. 2. Graph of internal compressive stresses of DLC with different $\mathrm{sp}^{2}$ and $\mathrm{sp}^{3}$ ratios [10].

PVD (Physical Vapour Deposition) [9,11,12]. However, all methods need to be balanced as they can cause problems within the resultant coating. Traditionally CVD processes typically take place at high temperatures up to $800-900{ }^{\circ} \mathrm{C}$, depending on material. Fortunately most modern deposition can take place at much lower temperatures ( $<0-400^{\circ} \mathrm{C}[9]$ ), allowing the coatings to be deposited more easily and on a greater range of substrates. Previous work has shown that DLCs have a temperature dependency in both service and deposition, where the tribological properties start to degrade (higher friction, more rapid wear) at elevated temperatures (>200 C) [13,14].

For hydrogenated coatings, a hydrocarbon(such as methane, $\mathrm{CH}_{4}$ )is used as the source material during deposition. For higher levels of hydrogen content, shorter hydrocarbon chains with greater ratios of carbon to hydrogen are used. Solid carbon sources such as graphite or carbon-carbon composites are used for coatings with low or no hydrogen. The ratio of $\mathrm{sp}^{2}$ and $\mathrm{sp}^{3}$ bonds is determined during coating synthesis by the impact energy of the depositing molecules, which is dictated by the bias voltage of the deposition [15]. At very low energies a non-DLC carbon polymer forms. At mid-levels of energy there is less hydrogen and $\mathrm{sp}^{3}$ structures are more common. At the high energies $(-1 \mathrm{kV}$ to $-3 \mathrm{kV})$ graphite like $\mathrm{sp}^{2}$ structures are prevalent due to an increase in unordered bonding [9].

In addition to CVD and PVD coating manufacture, other processes can be used instead of, or during production, to change properties. These include ion beam deposition [16], pulsed laser ablation [17] and ion beam conversion [18]; each method can be used to create desirable coating properties. For example ion beam conversion can be used to dope DLC coatings with elements such as sulphur, fluorine or nitrogen that serve to reduce friction [19].

\subsection{Interlayers}

DLC coatings can suffer from high levels of residual stress because of their structure. This can cause poor surface adhesion, leading to early delamination in the coatings. One of the main ways to combat the poor surface adhesion (due to high levels of residual stresses) is by depositing interlayers. These are thin coating layers of a material that will promote adhesion of the DLC. The interlayer must bond strongly to both the substrate and the DLC top layer (or a second interlayer). Common materials used as interlayers include titanium (Ti), chromium carbide $(\mathrm{CrC})$ and silicon nitride $\left(\mathrm{Si}_{3} \mathrm{~N}_{4}\right)$.

The interlayer can also help improve the corrosion resistance, as DLC coatings can be both porous and conducting, thus the interlayer can offer a physical barrier between the substrate and the corrosive environment the risk of delamination. 


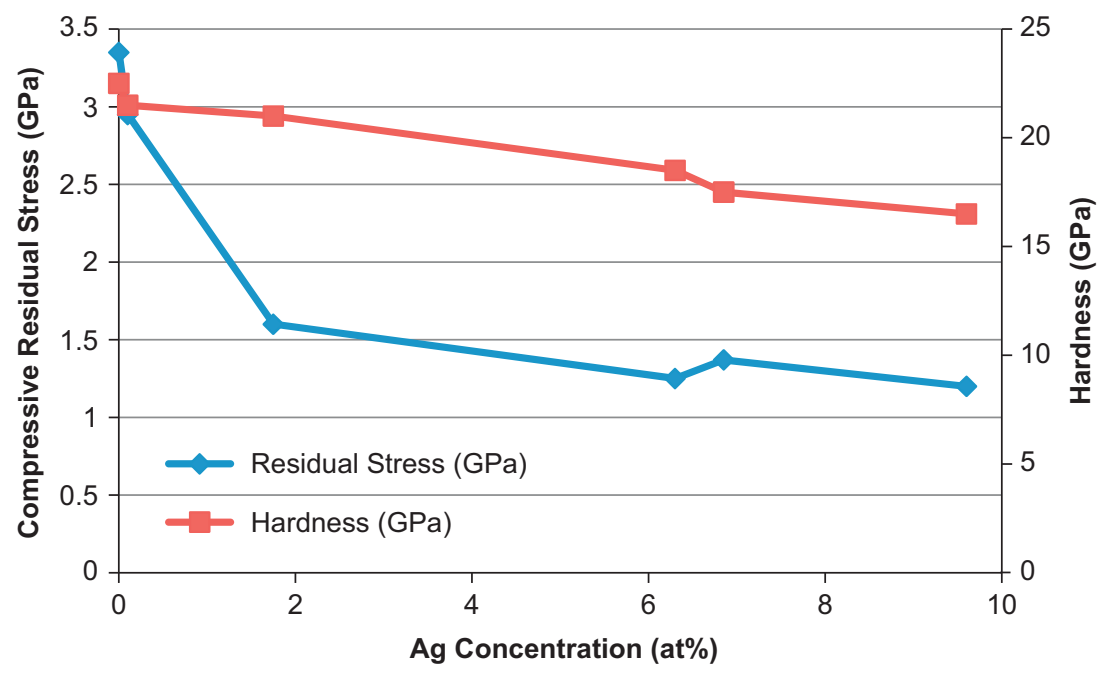

Fig. 3. Graph showing the effect of Silver doping in DLC films deposited on Si [31].

\subsection{Dopants}

Doping DLCs is another method of improving their DLC coating properties. Common doping elements include silver (Ag), nitrogen $(\mathrm{N})$,fluorine (F) and titanium (Ti). Most of these are beneficial as they reduce the residual stresses in the coating, without compromising the wear and corrosion performances. Fig. 3 shows how silver can reduce the residual stress of the coating, with only a slight reduction in the hardness of the coating also reported. Titanium also reduces the residual stress by reducing the amount of $\mathrm{sp}^{3}$ in the matrix, as well as improvements in the bonding between the substrate and the coating, further preventing delamination [20]. Titanium has also been shown to inhibit the growth of osteoclasts and other bone resorbing cells, improving the effectiveness of implants in situations where osseointegration is required [7].

XPS analysis of a silver doped DLC coating indicates this silver exist within the carbon matrix, remaining in a metallic state, without bonding to the carbon atoms. However the research provides no information about the size and distribution of the deposits in the matrix [21].

\subsection{Past use in biological conditions}

Ever since the development of DLC coatings their high wear and corrosion resistance has driven research towards implementation in the human body. Early testing indicated excellent tribo-corrosion performance, low toxicity to the body, and healthy interactions with the cells in the body, providing a safe growth surface. However, initial in vivo testing showed significant number of failures in the implants, which will be discussed in detail in Section 4.1.

DLCs can be found in various biomedical applications such as arterial stents, ophthalmic surgery needles, medical wires and contact lenses [6]. These different applications utilise different coating properties. For example, contact lenses have been used with DLC coatings due to their ability to reject biofilms formation. Ophthalmic surgery needles use DLC coatings as they maintain the sharpness of the needle, requiring less pressure to penetrate the tissues of the eye.

\section{DLC in the body}

The reaction of the body to a foreign object is one of the most important factors governing the success of an implant. Implant rejection will lead to failure and the need to remove the implant. Any material inserted into the body will come into contact with one or more body fluids and within a matter of seconds become coated in proteins. Due to the proteins' different affinities for the surface and the nature of the physiological conditions, there will be competitive adsorption between the different proteins. This protein adsorption is crucial to the body's response to the material, as the type of proteins adsorbed to the surface and their conformation will govern the cellular response to it. There is still disagreement on how the properties of the DLC surface affect protein adsorption, with some research suggesting hydrophilic surfaces are better for bearing surfaces and others suggesting hydrophobic surfaces are best [8,22-25].

DLC coatings have been investigated for use in biomedical situations [6,26-32]. They have been shown to not only have excellent bio- and hemo-compatibility, but the ability to tailor their surface by doping and compositional variations to the role they are required for has proven valuable. Cells have already been grown successfully on DLCs, including macrophages, fibroblasts and other human tissues [6].

The biological effect of DLC wear debris has been tested by growing bone marrow cells in presence of DLC film fragments (from a deliberately delaminated sample). No cellular damage was recorded compared to the control samples [7], suggesting they would make good implant coatings.

The double bonds in the carbon can also be beneficial in the body with evidence that they can be used to remove superoxide radicals $\left(\mathrm{O}_{2}^{\bullet-}\right)$ that cause tissue damage including strokes and cancer [33]. These are naturally generated in the body when neutrophils and immune cells attack pathogens in the body. The double bond (such as those found in $\mathrm{sp}^{2}$ ) reacts with this reactive oxygen and removes it. This effect has been shown using a modified buckminsterfullerene $\left(C_{60}\right)$ molecule, but the research suggests that the same reaction could be transferred to the DLC bond. This effect could be useful in the implantation, as the time where the wound is new or open is the most likely time for an external infection to occur, and this could help limit any damage to the surrounding body from the immune systems response, but would have no direct effect on preventing or curing the infection. However, the effects of breaking the double bonds on the material properties of the coating are not currently known.

\subsection{Antibacterial effects of DLC and doped DLC}

The national joint registry for England and Wales [1] states that between 2006 and 2009, a total of 25,222 single and two 
stage hip revision surgeries were undertaken, with 7.5\% (1891) of these revisions being attributed to infection. Of these, 1353 (71.5\%) were the more costly, difficult and traumatic two stage revisions. Therefore, a coating that could offer antibacterial properties, reducing the risk of infection, is extremely desirable.

Marciano et al.[34] tested a DLC coated $316 \mathrm{~L}$ stainless steel substrate, with a silicon interlayer, against a variety of different bacterium (Escherichia coli ATCC 25922, Pseudomonas aeruginosa ATCC 27853, Salmonella typhimurium ATCC 14028, and Staphylococcus aureus ATCC 25923), to determine the natural antibacterial properties. The results indicated that the undoped DLC was harmful to bacteria ( $E$ coli and Salmonella) in direct contact the surface. Also films with low hydrogen content and hydrophobic properties increased the rate of bactericidal activity. It was suggested by the researchers that the carbon aggregates on a nanoscale level causes physical damage to the outer membrane of the bacteria cells, leading to cell death and the release of their intracellular content. This, however, presents a potential problem, as the same process could also damage the living tissue cells of the host.

Earlier work by the same author (Marciano et al. [35]) used a layered system, where a thin layer of a-C:H DLC was deposited, followed by the application of a layer of silver nanoparticles. This process was repeated 4-10 times to give a multilayer system and showed promise in sterilisation tests reaching a $69 \%$ bactericidal rate when exposed to $E$ coli bacteria for $3 \mathrm{~h}$, compared to a $0 \%$ rate for stainless steel and 30\% for pure a-C:H film. The bactericidal rate was calculated using Eq. (1)

Rate $(\%)=\left(\frac{(B-C)}{B}\right) \times 100$

where $B$ is the mean number of bacteria on the control samples and $C$ the mean number on test samples surface. However, after a test period of $24 \mathrm{~h}$ the bactericidal rate had fallen dramatically to $30 \%$ for silver-doped DLC, while the pure DLC increased to $38 \%$ (Fig. 4),when compared to the control solution of Gentamicin (an antibiotic) with a concentration of $10 \mathrm{mg} / \mathrm{mL}$ (bacteria-laden gel was washed with solution), and an uncoated stainless steel control sample. This suggests that silver added into the coating is effective, but mostly only at shorter exposure periods [35]. After $24 \mathrm{~h}$ the steel sample showed a slight bactericidal activity, suggesting that in long term tests there will likely be natural cell death. For longer timeframes (e.g. over $24 \mathrm{~h}$ ) it appears that an undoped DLC coating is more effective, as the doped samples performance is diminished due to the reduction of active surfaces.
The study [35] mentions a drop in hardness from 19 GPa to 11-16 GPa, a drop that is consistent with silver inclusion into the film (Fig. 3), but speculates that the improvement in other properties (lower residual stress)will counterbalance the reduction. However, as the paper does not look at the wear performance of these doped coatings this cannot be confirmed. Another question left unanswered is whether when the sample wears would more silver nanoparticles be released, increasing the level of anti-bacterial effectiveness? Also would the levels of wear needed for nano-particle's release make this a viable option?

Silver is known as an antibacterial agent $[28,29]$. Nanoparticles of silver are being phased in as a potential alternative to standard antibacterial treatments, as they offer the possibility of bacterial immunity, without the risk of increasing the bacteria's resistance to conventional medication. However, the reasons for its' antibacterial resistance and growth inhibition are not very well understood. The most common theory is that the generation of silver ions attack the membrane lipids, causing a breakdown in membrane functions [36]. The cells (of the bacteria) become less permeable and the bacteria die. This has been confirmed by ESR spectra imaging (Electron Scanning Resonance) [29].However some of the by-products of the process of lipid breakdown can be potentially mutagenic and carcinogenic [37]. Since this process occurs in the body naturally with the oxidation of polyunsaturated fatty acids, it can be assumed to be relatively safe to human health on such a small scale, however, long term toxicity needs to be addressed.

Other research [28]also suggests that the silver cations causes some form of damage to DNA, preventing replication and denaturing cellular proteins. TEM (Transmission Electron Microscopy) studies [28] showed that the bacteria absorbed silver nanoparticles into their membranes, while other cells leaked intracellular substances. Evidence that the nanoparticles coagulate on the surface of the $\mathrm{E}$ coli bacteria has also been observed. However, the antibacterial effect was limited; it works best on solid nanoparticle deposition on bacteria cultures. When suspended in a liquid medium they merely delay the onset of bacteria growth, even at high concentrations, which is visible in TEM analysis. Nanoparticles coagulate around dead cells and do not move on to react with new bacterium[28]. Sondi and SalopekSondi [28] observed that despite high initial silver concentrations the concentration reduces as time passes, indicating that silver particles in suspension cannot provide long lasting resistance, but that they can provide protection against early infection.

Another investigation [30] showed that silver doped ta-C DLC on a titanium substrate is more effective as an antibacterial agent

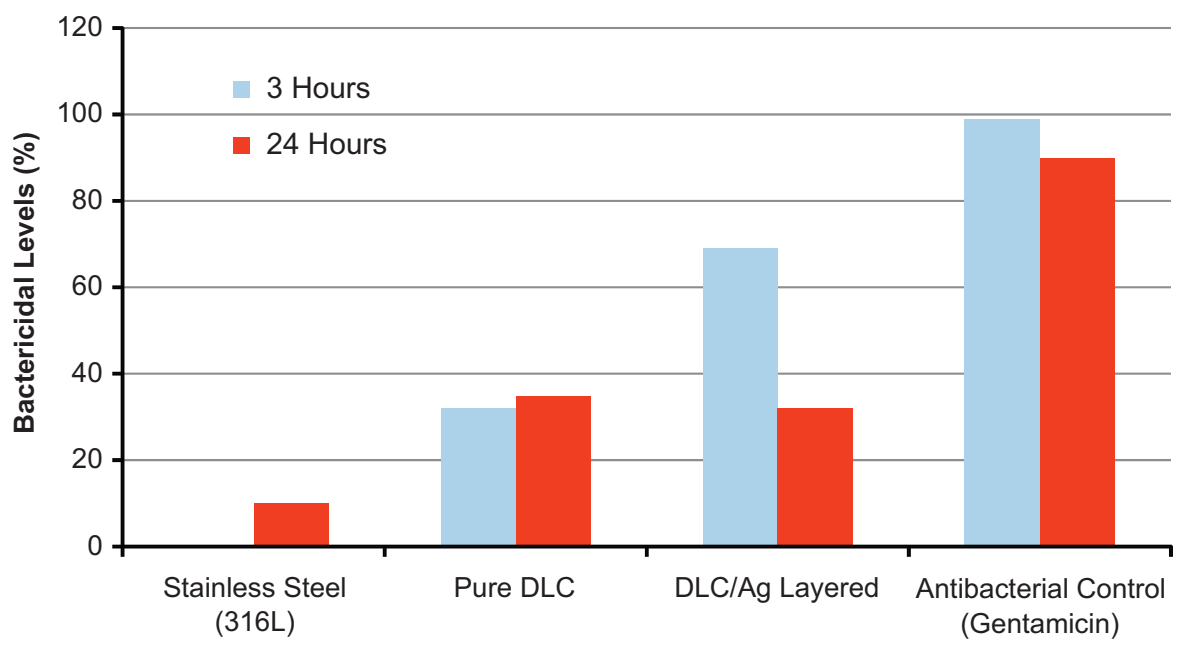

Fig. 4. Graph to show effect of silver in DLC (316 L stainless steel substrate) on bactericidal levels [35]. 
than a undoped ta-C DLC coating, or the bare substrate. However no value for the silver dopant level was provided for the antibacterial tests. Over a $24 \mathrm{~h}$ period the silver doped sample reduced bacteria density down to $1.07 \times 10^{-6} \mathrm{~mm}^{-2}$ compared to the uncoated remained at $2.58 \times 10^{-6} \mathrm{~mm}^{-2}$. Although this shows comparative improvement compared to the uncoated sample, the paper does not state the initial density, for a reduction rate to be possible, although the imaging of the surface gives a visual confirmation that the difference between the 2 samples is significant. Another set of samples (with 3.5\% and 6.5\% silver dopants in DLC) were tested with glioma cells, which are related to tumour formation, from a rat. Over a period of 5 days the DLC with a 6.5 at\% of silver doping produced a higher rate of cell death (66.7\%) compared to the uncoated $\mathrm{Ti}(33.2 \%)$ and undoped DLC (39.9\%). It is unknown if this can be related to antibacterial applications, but also showed the potential toxicity of silver in the body as the cells tested where naturally occurring biological cells not bacterium [30].

\section{DLC testing for its use as an implant coating}

The next sections will look at the tribological performance of DLC coatings for joint replacement applications, ranging from fundamental in vitro testing through to in vivo performance.

\subsection{Explant study}

There are a limited number of detailed studies on DLC coated implants and explants. However, Taeger et al. [38] compared the performance of a DLC coated Titanium alloy (Ti-6Al-4V) head with $\mathrm{Al}_{2} \mathrm{O}_{3}$ ceramic heads, both wearing against a UHMWPE cup. 202 patients were submitted to the trial, with 101 having an implant with a coating and 101 having ceramic head. The surgeries were carried out in April 1993-January 1995. After an average of 9 years (8.5-10.1 years) 178 of the samples were retrieved. Of the remaining patients, 10 ( 5 of each coating) were unavailable for follow-up and a further 14 patients ( $9 \mathrm{DLC}$ and $5 \mathrm{Al}_{2} \mathrm{O}_{3}$ ) had unfortunately died during the time

Table 1

Table of reasons for implant revisions.

\begin{tabular}{lll}
\hline Reason for revision & DLC coated Ti-6Al-4V & Uncoated $\mathbf{A l}_{\mathbf{2}} \mathbf{O}_{\mathbf{3}}$ \\
\hline Total (of total 178 follow-ups) & $46(25.8 \%)$ & $21(11.8 \%)$ \\
Aseptic Loosening & 41 & 10 \\
Ossifications & 1 & 6 \\
Dislocations & 0 & 3 \\
Pain & 2 & 2 \\
Infection & 1 & 0 \\
Implant Failure & 1 & 0 \\
\hline
\end{tabular}

period. One of these deaths (in a DLC patient) was linked to early infection in the wound (no further information provided), but the other 13 were unrelated to the hip replacement. In 9 years since implantation 67 patients had required revisions, the reasons for which are detailed in Table 1 . More of the DLC coatings required revisions than the ceramic heads, with 4 times more failures caused by aseptic loosening (41 compared to 10 ). The average time before revision for the DLC cups was very similar to the alumina; 3.9 years (ranging between 0.2 and 9.2 years) and 4.1 years (0.4-8.7 years) for the DLC and alumina respectively. However the DLC had no failures due to aseptic loosening in the first year and half, unlike the ceramic heads, which first showed aseptic failure after 9 months

The retrieved DLC samples all showed visible pitting as shown in Fig. 5 SEM analysis showed that the pitting was localised delamination of the DLC. This delamination is thought by Taeger et al. to be the major cause of failure through aseptic loosening of the implants, as the loose DLC material triggers an adverse reaction.

It was noted that the DLC coating in this study was deposited directly onto the Ti-6Al-4V substrate without the use of an interlayer. With new advances in deposition methods and interlayer usage it would be expected that coating performance should improve significantly. Taeger et al. [38] paper concluded that although the DLC has excellent properties and shows excellent promise, the differences between the in vitro testing methods and conditions, from those experienced in vivo, were major contributing factors to the resultant implant performance. Therefore although in vitro tests are not as accurate they are still important, but the reasons for the difference between in vivo and in vitro need to be explored

\subsection{Pin on disc testing}

Pin on disc testing as a group is the most common testing method published in literature. Although it can provide a good base of knowledge of the properties and basic tribological performance, they are of limited use for assessing implant coatings. Data gleaned from these tests provides only limited insight into probable application behaviour. Table 2 displays an overview of the pin on disc testing conditions used and the overall results.

There is a significant amount of variance in test results, which could be the result of inconsistent testing conditions and materials. Out of 14 reports [4,27,39-50] there appeared to be no standardisation between choice of testing conditions and counter surface.

Only 2 of the tests used similar loading $[46,47]$, but without the relevant information it is hard to compare this to the papers that only present the maximum contact pressure. This variance is continued through the number of cycles tested with some papers testing under as few as 3600 cycles $(90 \mathrm{~m}$ ) [45], some testing over a million cycles (44 and $100 \mathrm{~km}$ ) [46,48], again with no commonality
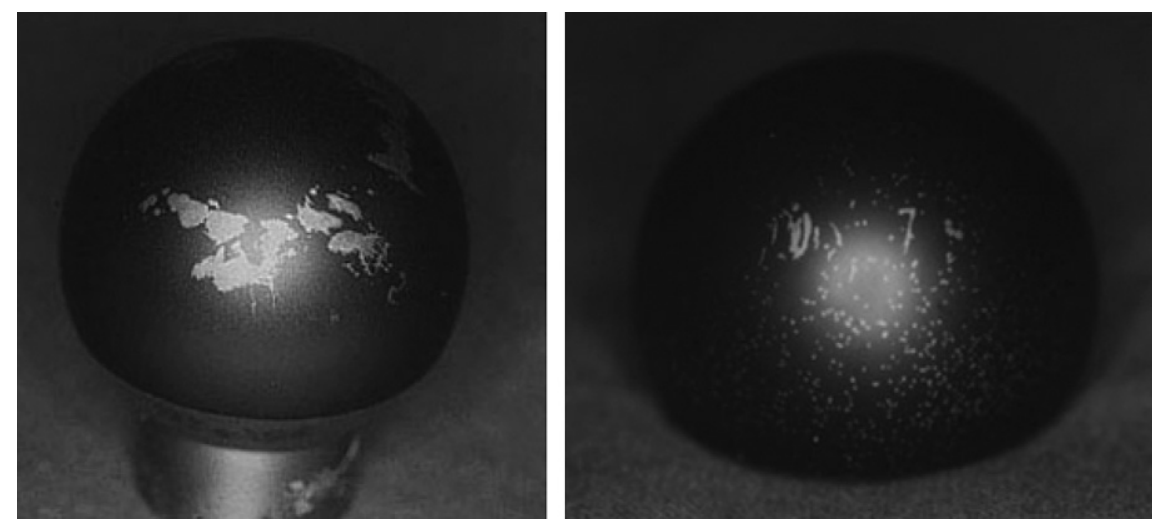

Fig. 5. Retrieved DLC coated acetabular heads, showing pitting, detached coating and underlying CoCrMo substrate [38]. 
Table 2

Review of published Unidirectional pin-on-disc results.

\begin{tabular}{|c|c|c|c|c|c|c|c|c|}
\hline \multicolumn{9}{|l|}{ Pin on Disk } \\
\hline Source & Disc material & $\begin{array}{l}\text { Pin } \\
\text { material }\end{array}$ & Load & $\begin{array}{l}\text { Maximum contact } \\
\text { pressure }\end{array}$ & Speed & $\begin{array}{l}\text { Cycles and/or } \\
\text { sliding distance }\end{array}$ & Lubrication & Pin wear \\
\hline \multirow[t]{2}{*}{$\begin{array}{l}\text { Lappalainen } \\
\text { et al., } 1998\end{array}$} & \multirow[t]{2}{*}{$\begin{array}{l}\text { DLC on CoCrMo, steel (AISI316L), } \\
\text { Steel (AISI420), Ti-6Al-4V }\end{array}$} & $\mathrm{Al}_{2} \mathrm{O}_{3}$ & $617 \mathrm{~N}$ & & $\begin{array}{l}0.068 \mathrm{~m} / \\
\mathrm{s}\end{array}$ & & $\begin{array}{l}50 \% \text { humid } \\
\text { air }\end{array}$ & \\
\hline & & UHWMPE & & 24 and $145 \mathrm{MPa}$ & $\begin{array}{l}0.045 \mathrm{~m} / \\
\mathrm{s}\end{array}$ & 50,000 & $1 \% \mathrm{NaCl}$ & $\begin{array}{l}\text { Improved Wear } \\
\text { resistance } 30-600 \\
\text { times }\end{array}$ \\
\hline \multirow[t]{6}{*}{$\begin{array}{l}\text { Shiet al., } \\
2003\end{array}$} & \multirow[t]{6}{*}{ Stainless steel $440 \mathrm{C}$} & $440 C$ steel & $50 \mathrm{~N}$ & & $0.05 \mathrm{~m} / \mathrm{s}$ & $3600(90 \mathrm{~m})$ & $\begin{array}{l}\text { Bovine } \\
\text { serum }\end{array}$ & $1.55 \times 10^{6} \mu \mathrm{m}^{3}$ \\
\hline & & $\mathrm{Al} 2 \mathrm{O} 3$ & & & & & & $3.79 \times 10^{6} \mu \mathrm{m}^{3}$ \\
\hline & & ZrO2 & & & & & & $3.24 \times 10^{6} \mu \mathrm{m}^{3}$ \\
\hline & & DLC & & & & & & $3.4 \times 10^{4} \mu \mathrm{m}^{3}$ \\
\hline & & coated & & & & & & \\
\hline & & $440 \mathrm{C}$ & & & & & & \\
\hline \multirow{4}{*}{$\begin{array}{l}\text { Xu and Pruitt, } \\
1999\end{array}$} & Uncoated CoCrMo & \multirow[t]{4}{*}{ UHWMPE } & \multirow[t]{4}{*}{9.79} & \multirow[t]{4}{*}{$\begin{array}{l}30 \mathrm{MPa}(\max ) \\
6-7 \mathrm{MPa} \text { (steady state) }\end{array}$} & \multirow[t]{4}{*}{$\begin{array}{l}0.044 \mathrm{~m} / \\
\mathrm{s}\end{array}$} & \multirow[t]{4}{*}{1 million, 44 km } & \multirow[t]{4}{*}{$\begin{array}{l}\text { Distilled } \\
\text { water }\end{array}$} & $2.22 \times 10^{-7} \mathrm{~mm}^{3} \mathrm{Nm}^{-1}$ \\
\hline & 2 layer DLC & & & & & & & $1.13 \times 10^{-7} \mathrm{~mm}^{3} \mathrm{Nm}^{-1}$ \\
\hline & 3 layer DLC & & & & & & & $1.3 \times 10^{-7} \mathrm{~mm}^{3} \mathrm{Nm}^{-1}$ \\
\hline & 5 layer DLC & & & & & & & $0.62 \times 10^{-7} \mathrm{~mm}^{3} \mathrm{Nm}^{-1}$ \\
\hline \multirow[t]{4}{*}{$\begin{array}{l}\text { Sheeja et al., } \\
2001\end{array}$} & Uncoated CoCrMo & \multirow[t]{4}{*}{ UHWMPE } & \multirow[t]{4}{*}{$10 \mathrm{~N}$} & & \multirow[t]{4}{*}{$0.06 \mathrm{~m} / \mathrm{s}$} & $30,0001.507$ km & \multirow[t]{4}{*}{$\begin{array}{l}\text { Simulated } \\
\text { body fluid }\end{array}$} & $4.97 \times 10^{-7} \mathrm{~mm}^{3} \mathrm{Nm}^{-1}$ \\
\hline & DLC coated CoCrMo & & & & & & & $5.31 \times 10^{-7} \mathrm{~mm}^{3} \mathrm{Nm}^{-1}$ \\
\hline & Uncoated CoCrMo & & & & & $120,0006.031 \mathrm{~km}$ & & $1.65 \times 10^{-7} \mathrm{~mm}^{3} \mathrm{Nm}^{-1}$ \\
\hline & DLC coated CoCrMo & & & & & & & $2.02 \times 10^{-7} \mathrm{~mm}^{3} \mathrm{Nm}^{-1}$ \\
\hline \multirow{5}{*}{$\begin{array}{l}\text { Dong et al., } \\
1999\end{array}$} & Uncoated $\mathrm{Ti}$ & \multirow[t]{5}{*}{ UHWMPE } & & $5 \mathrm{MPa}$ & $0.25 \mathrm{~m} / \mathrm{s}$ & $100 \mathrm{~km}$ & Distilled & $3.77 \times 01^{-6} \mathrm{~mm}^{3} \mathrm{Nm}^{-1}$ \\
\hline & DLC & & & & & & & $8.88 \times 10^{-8} \mathrm{~mm}^{3} \mathrm{Nm}^{-1}$ \\
\hline & OD (oxygen diffusion) & & & & & & & $4.18 \times 10^{-8} \mathrm{~mm}^{3} \mathrm{Nm}^{-1}$ \\
\hline & Ion implant & & & & & & & $2.86 \times 10^{-8} \mathrm{~mm}^{3} \mathrm{Nm}^{-1}$ \\
\hline & TO (thermal oxidation) & & & & & & & $1.15 \times 10^{-8} \mathrm{~mm}^{3} \mathrm{Nm}^{-1}$ \\
\hline
\end{tabular}

between tests. The speeds are mainly similar, all around $0.05 \mathrm{~ms}^{-1}$, with the exception of Dong et al. [48], who used a much higher speed.

The variance is redisplayed in the overall performance of the samples, with Lappalainen et al. [44] displaying an ability to improve pin wear resistance by a factor of up to 600 , while Sheeja et al. [47] only found a reduction by a factor of 4 . Two papers both show a 40 times reduction in wear, showing the only common value for wear, however as one paper presents the data as wear volume, the other as wear rate it is hard to compare the results to each other. The largest reduction value (the factor of 600) has no clear reason for the large variance, as it is neither the shortest of longest test, nor is it the highest or lowest load. The only significant difference is that it is the only test using $\mathrm{NaCl}$ solution, which although it can provide the corrosive environment of a true in vitro test it provides none of the biological activity, such as protein adsorbtion onto the surface. However, it seems unlikely that this could cause such a significant difference in results.

One clear problem with these results is that the papers only comment on the wear of the pin itself, which is only the coated surface in one of the tests. Therefore although the effect of a coated surface on the polymer is well documented there are no quantative values for the wear of the DLC coated disc sample. By ignoring one half of the tribological system the data is less than useful for real application use as reducing any wear debris is crucial from both contacts.

\subsection{Hip simulator testing}

Multi-station hip simulator testing rigs can produce more realistic conditions experienced by an implant (compared to other laboratory test rigs), such as multidirectional movement and loading. Table 3 shows a summary of the results from the hip simulator testing of DLC coated implants.

Hip simulator testing also shows variance in testing conditions, but not to as large a degree as the pin on disk tests. This is to be expected as simulator testing is standardised. However, there is still large variation in the testing fluid and materials.

Tiainen, Lappalainen et al. and Fisher et al. all used DLC coated CoCrMo against another coated surface using similar loading, but over different testing times (Tiainen and Fisher et al. tested for 2 million cycles, whereas Lappalainen et al. tested for longer, with 15 million cycles). They also all tested in a pseudo-physiological solution, although Tiainen's was a $1 \% \mathrm{NaCl}$ solution compared to the dilute bovine serum used by the other two. The results showed similarities, with all 3 tests showing a reduction in wear compared to uncoated tests, however to different levels. Tiainen [27] showed a reduction in wear by a factor of $10^{5}-10^{6}$, Lappalainen et al. [39] only showing a reduction of $10^{2}-10^{4}$ and Fisher et al. [42] only showing a wear rate reduction of 26.The only notable differences between these tests is that Fisher et al. tested the DLC coating against a different hard coating $(\mathrm{CrN})$ not a 2nd DLC surface and a slightly different testing rig

Papers that use DLC on UHMWPE(Saikko et al. [43], Affatato et al. [41] and Dowling et al. [40]) use similar testing periods and testing solutions. However, Affatato et al. [41] used double the test load that Saikko et al. [43] employed. So although the results are similar (Affatato et al. showing DLC to offer a very slight improvement, Saikko et al. showing it is virtually the same, if a little worse than using an uncoated sample) they are difficult to compare due to such a simple difference in test conditions. The other testing using UHMWPE were performed by Dowling et al. [40].The study used a similar testing period, but a different testing solution (distilled water) with no information on the loading provided, making its' 
findings of a wear volume reduction by a factor of 18 very difficult to compare to that of the other two tests.

Overall hip simulator testing seems to be positive with DLC showing an improvement compared to uncoated samples in all tests. However, the margin of improvements varies wildly between tests (likely due to the broad range of test conditions), and in some papers is not as good as the improvements offered by other hard coatings.

\subsection{Other bio-tribology experimentation}

In addition to the most common testing methods of pin on disc and hip simulators, some research uses alternative testing methods.

Thorwarth et al. [49] used a spine disk simulator and compared a DLC (a-C:H) with various surface finishes against another DLC coated surface and compared them to uncoated CoCrMo coupling of similar surface roughness, at a high loading of $1200 \mathrm{~N}$ in bovine serum. Although for hips this is not high, it is for a spine disk. The uncoated CoCrMo started with low wear, but this increased significantly after 7 million cycles. By contrast a DLC with a thicker $(16 \mu \mathrm{m})$, rougher surface had a similar wear performance as an uncoated sample until 7 million cycles, and then it remained lower. However, the lowest wear rate resulted from the samples coated with thin $(4 \mu \mathrm{m})$, smooth DLC, which remained low for the entire test, with a volume loss of less than $0.1 \mathrm{~mm}^{3}$ after 20 million cycles, compared to $0.6 \mathrm{~mm}^{3}$ for the thicker DLC, and $1.1 \mathrm{~mm}^{3}$ for the uncoated CoCrMo. As the paper doesn't mention the contact pressure it is hard to compare this to other testing rigs due to the difference in geometry and loading.

Oñate et al. [50] used a knee simulator with medium load $(500 \mathrm{~N})$ and tested in body temperature distilled water. This loading is considered medium for the role of the implant. The DLC coating (type not mentioned) on CoCrMo was tested in a rolling, sliding motion against a UHMPWE plate. It showed a 4-5 times reduction in wear on the UHMPWE, when compared to an uncoated CoCrMo sample. Also tested were other hard coatings on the alloy. The TiN coating increased the wear on the polymer counter surface by a factor of 5 when compared to the uncoated sample. Using a ceramic $\mathrm{Al}_{2} \mathrm{O}_{3}$ surface against the polymer showed less wear than the uncoated CoCrMo alloy, but higher than the DLC coating. Only $\mathrm{N}^{+}$ion implantation on the CoCrMo produced slightly better results than the DLC coated surface ( $0.130 \mathrm{mg}$ of UHMWPE wear compared to $0.150 \mathrm{mg}$ for DLC and $0.690 \mathrm{mg}$ for uncoated).

Although both of these papers are researching different applications they are still for load bearing biological applications meaning they can show the success of the coating.

\subsection{Suggested reasons for coating failure in in vitro testing}

Affatoto et al. [41] suggested that the poor performance of the DLC films in general is due to their adhesion on the substrate as no interlayer was used. Ti and Co alloys are both poor at forming

Table 3

Review of published hip simulator test results.

\begin{tabular}{|c|c|c|c|c|c|c|c|}
\hline \multicolumn{8}{|l|}{ Hip simulator } \\
\hline Source & Material & Material & Load & Frequency & Cycles & Lubrication & Wear \\
\hline Tiainen, 2001 & $\begin{array}{l}\text { DLC on stainless } \\
\text { steel (AISI316L) }\end{array}$ & $\begin{array}{l}\text { DLC on stainless } \\
\text { steel (AISI316L) }\end{array}$ & $500 \mathrm{~kg}$ & $1 \mathrm{~Hz}$ & 2 million & $\begin{array}{l}1 \mathrm{wt} \% \mathrm{NaCl} \\
\text { solution }\end{array}$ & $\begin{array}{l}10^{5}-10^{6} \text { reduction } \\
\text { compared to CoCrMo }\end{array}$ \\
\hline \multirow[t]{2}{*}{$\begin{array}{l}\text { Lappalainen } \\
\text { et al., } 2002\end{array}$} & CoCrMo & UHMWPE & $\begin{array}{l}3000 \text { N (Paul Gait } \\
\text { Curve) }\end{array}$ & $\begin{array}{l}1 \mathrm{~Hz} \text { (Rotation reversed } \\
1000 \text { cycles) }\end{array}$ & 15 million & $\begin{array}{l}\text { Diluted bovine } \\
\text { serum EDTA }\end{array}$ & $50-100 \mathrm{~mm}^{3} /$ year \\
\hline & $\begin{array}{l}\text { CoCrMo } \\
\text { DLC on stainless } \\
\text { steel (AISI316L) }\end{array}$ & $\begin{array}{l}\text { CoCrMo } \\
\text { DLC on stainless } \\
\text { steel (AISI316L) }\end{array}$ & & & & & $\begin{array}{l}1-5 \mathrm{~mm}^{3} / \text { year } \\
<10^{-4} \mathrm{~mm}^{3} / \text { year }\end{array}$ \\
\hline \multirow{3}{*}{$\begin{array}{l}\text { Dowling et al., } \\
1997\end{array}$} & Stainless Steel & UHMWPE & & & 6 million & Distilled water & $72 \mathrm{~mm}^{3}$ \\
\hline & Zirconia & & & & & & $\begin{array}{l}15 \mathrm{~mm}^{3} \text { (Ended at } \\
5 \text { million) }\end{array}$ \\
\hline & $\begin{array}{l}\text { DLC on stainless } \\
\text { steel }\end{array}$ & & & & & & $4 \mathrm{~mm}^{3}$ \\
\hline \multirow[t]{4}{*}{$\begin{array}{l}\text { Affatato et al., } \\
2000\end{array}$} & Steel AISI316L & UHMWPE & $\begin{array}{l}2030 \mathrm{~N} \text { sinusoidal } \\
\text { load }\end{array}$ & $1 \mathrm{~Hz}$ & 5 million & $\begin{array}{l}\text { Diluted bovine } \\
\text { serum EDTA }\end{array}$ & $177 \mathrm{mg}$ \\
\hline & CoCrMo & & & & & & $167 \mathrm{mg}$ \\
\hline & Alumina & & & & & & $134 \mathrm{mg}$ \\
\hline & DLC on Ti Alloy & & & & & & $127 \mathrm{mg}$ \\
\hline \multirow[t]{5}{*}{$\begin{array}{l}\text { Fisher et al., } \\
2002\end{array}$} & CoCrMo & CoCrMo & $\begin{array}{l}3000 \text { N Max (Paul } \\
\text { Gait Curve) }\end{array}$ & $1 \mathrm{~Hz}$ & 2 million & $\begin{array}{l}25 \% \text { diluted } \\
\text { bovine serum }\end{array}$ & $2.5 \mathrm{~mm}^{3}$ \\
\hline & TiN on CoCrMo & & & & & & $2.7 \mathrm{~mm}^{3}$ \\
\hline & $\mathrm{CrN}$ on CoCrMo & & & & & & $0.45 \mathrm{~mm}^{3}$ \\
\hline & $\mathrm{CrCN}$ on CoCrMo & & & & & & $0.35 \mathrm{~mm}^{3}$ \\
\hline & DLC on CoCrMo & & & & & & $0.2 \mathrm{~mm}^{3}$ \\
\hline \multirow[t]{6}{*}{$\begin{array}{l}\text { Fisher et al., } \\
2004\end{array}$} & CoCrMo & CoCrMo & & $1 \mathrm{~Hz}$ & 2 million & $\begin{array}{l}25 \% \text { diluted } \\
\text { bovine serum }\end{array}$ & $1.05 \mathrm{~mm}^{3} / 10^{6}$ cycles \\
\hline & TiN on CoCrMo & TiN on CoCrMo & & & & & $0.08 \mathrm{~mm}^{3} / 10^{6}$ cycles \\
\hline & CrN on CoCrMo & CrN on CoCrMo & & & & & $0.07 \mathrm{~mm}^{3} / 10^{6}$ cycles \\
\hline & $\mathrm{CrCN}$ on $\mathrm{CoCrMo}$ & $\mathrm{CrCN}$ on CoCrMo & & & & & $0.06 \mathrm{~mm}^{3} / 10^{6}$ cycles \\
\hline & CrN on CoCrMo & TiN on CoCrMo & & & & & $0.05 \mathrm{~mm}^{3} / 10^{6}$ cycles \\
\hline & DLC on CoCrMo & & & & & & $0.04 \mathrm{~mm}^{3} / 10^{6}$ cycles \\
\hline \multirow[t]{3}{*}{$\begin{array}{l}\text { Saikkoet al., } \\
2001\end{array}$} & CoCrMo & UHMWPE & $\begin{array}{l}1000 \mathrm{~N} \text { sinusoidal } \\
\text { load }\end{array}$ & $1 \mathrm{~Hz}$ & 3 million & $\begin{array}{l}50 \% \text { diluted } \\
\text { bovine serum }\end{array}$ & $1.76 \times 10^{-6} \mathrm{~mm}^{3} / \mathrm{Nm}$ \\
\hline & Alumina & & & & & & $1.51 \times 10^{-6} \mathrm{~mm}^{3} / \mathrm{Nm}$ \\
\hline & DLC on CoCrMo & & & & & & $1.8 \times 10^{-6} \mathrm{~mm}^{3} / \mathrm{Nm}$ \\
\hline
\end{tabular}


strong interactions with the DLC, as the atoms might leach across to the film and weaken the interface between the coating and surface. A carbide layer of $\mathrm{Al}, \mathrm{Fe}, \mathrm{Ti}, \mathrm{Si}, \mathrm{Mo}$ and $\mathrm{Ge}$ can help improve this interaction. Delamination is a common failure mechanism observed in testing, and conforms with the main known drawbacks of DLC, i.e lack of surface adhesion. The high internal stresses are known to cause early delamination, which increases wear rates and failure to protect the substrate from the corrosive environment. Indeed this has been identified as the main cause for implant failure in the explant study by Taeger et al., as observed in Fig. 5 [38]. Fracture and cracking was noted along the wear scars by Fisher et al. [42], shown in Fig. 6, suggesting early delamination in the coating around the contact points. However, the paper does not mention whether an interlayer was used, which probably means one was not applied. Xu and Pruitt [46] also noted delamination in the samples (Fig. 7). Again no interlayer was used, instead a softer layer of DLC was deposited under a harder DLC coating to create a gradiated layer system design.

Any tribo-corrosion tests performed consisted of static corrosion testing, with no testing under loaded conditions being reported. Therefore corrosion induced delamination cannot be ruled out, making future in-situ electrochemical measurements that can potential detect delamination in progress useful.

\subsection{Suggested reasons for failure in implants, not related to coating}

Dong et al. [48] observed that in the uncoated titanium alloy samples, small pieces of worn oxidised titanium from the surface of the disc embedded in the UHMWPE counter-face and acted as an abrasive agent on the surface. This did not occur on the DLC coated samples, but it was noted under SEM that UHMPWE had detached from the counter-surface and became embedded in pits on the DLC surface. The transferred UHMWPE was found to have smeared across the DLC surface causing adhesive wear of the UHMWPE counter-face, likely increasing the coefficient of friction.

Sheeja et al. [47] suggested that harder surfaces should wear the softer ones. For instance in a DLC vs. UHMWPE contact, the higher hardness of the DLC will lead to the UHMWPE wearing more. This poses a potential problem for DLC's, as although they can vastly reduce their own wear, the increase in hardness (up to 5 times compared to uncoated CoCrMo) could vastly increase wear in the counter-face, due to the difference in hardness values

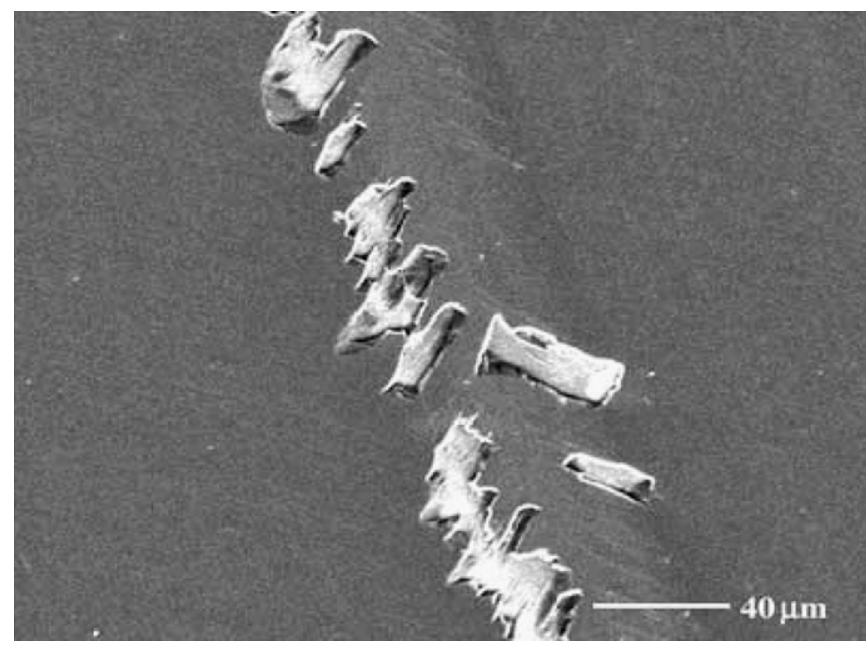

Fig. 6. Cracking of DLC coated insert worn against CrN coated CoCrMo [42]. between the coated surface and the counter-surface and the corresponding increase in abrasion.

As evidenced by the wear rates and sliding life, the carboncarbon interaction between the transfer layer on the counter surface and the original coated surface created adhesion between the surfaces. This might not be a problem in vivo as the transfer layer has been shown to not form in the body, either due to the natural bio film on the surface forming faster, or the constant motion in a fluid preventing it from attaching for long. This is why validation of in vitro results with those from explants is important.

The importance of surface roughness was investigated, and it was shown that the rougher surfaces promote earlier failure of the coating, with a critical surface roughness for the coating of $0.035 \mu \mathrm{m}$. This is caused by rougher surfaces having more asperities, resulting in a smaller contact area between the surfaces, increasing the contact stress and abrasion, and by smoother surfaces having more surface in contact, increasing the adhesion to the substrate.

$\mathrm{Xu}$ and Pruitt [46] showed that the polymer used against the DLC (multilayer, both a:C-H and a:C) was burnished and showed signs of fibrillation (Fig. 8). However the extent of this damage was reduced compared to uncoated surfaces. It was also reported

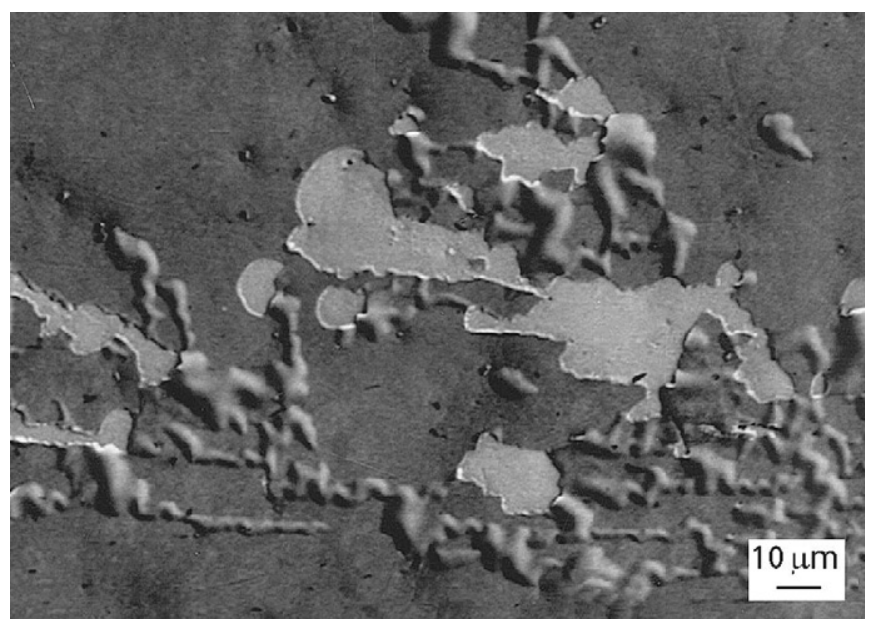

Fig. 7. Delamination observed on DLC sample on Ti-6Al-4V substrate after 1 million cycles in distilled water [46].

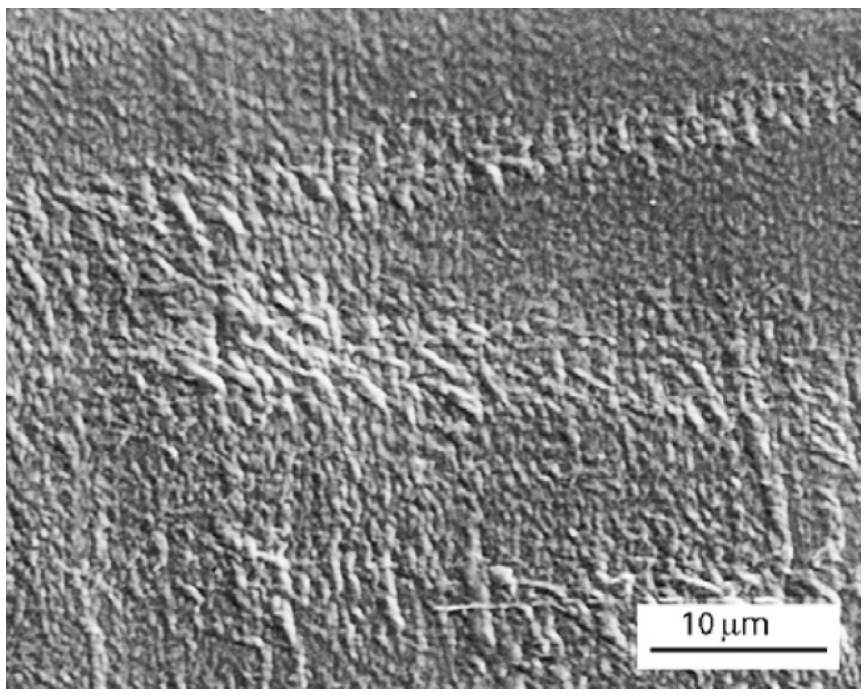

Fig. 8. SEM image of torn fibrils in UHMWPE after $11 \mathrm{~km}$ sliding against DLC in distilled water [46]. 
that the DLC caused a thin UHMWPE transfer film which reduces the wear of UHMWPE surface. The multilayer coating used in this study (different layers of DLC of alternating types on top of one another)reduced the residual stress and improved the coatings adhesion to the surface. However, the softer outer layer increased the surface interaction and friction, meaning it was less effective as a coating, but a separate coating system with more layers, but still a soft coating on top, decreased the wear in the polymer.

\section{Potential reasons for differing results}

As the previous sections have noted there is a disagreement amongst previous work as to the usefulness of DLC coatings for implants.

There are several potential reasons for these disagreements.

- There appears to be little consistency amongst testing methods and conditions - though most testing contains 1 or 2 common elements (such as UHMPWE as the counter surface) there is a large range in loading conditions, environment and materials combinations used.

- There also appears to be little information on the DLC coating system and deposition related parameters. A number of papers do not state the type of DLC used [4,40-43,46-48], while those that do state they are using ta-C or a-C:H, they fail to mention the composition ratio. While the manufacturing method and the source material enable an estimation of the composition, without knowing the exact conditions during the deposition, it remains little more than a guess. The presence or lack of an interlayer, is often not mentioned and these layers can make a large difference in the performance of the sample, particularly in its survivability, resistance to wear, deformation and corrosion control. Finally the thickness of interlayers and coatings are also often excluded, which again play a significant role in the coatings performance.

- Saikko et al. [43] noted that different serums can cause different results, due to the different types of biological interactions that occur and the severity of these interactions in the fluid. In addition to this, some serum tests use additives like EDTA to prevent the serum clotting, this can change the chemistry of the serum and the interactions of the proteins on the surface, affecting the overall performance. Some tests use $\mathrm{NaCl}$ solutions that can reflect the corrosive environment, but have none of the biological activity that could have a large effect on results.

The long term performance of new DLC coatings and interlayer combinations both in vivo and in vitro need to be determined. Previous research has suggested early delamination based failures, and this indeed occurred in large numbers of implanted DLC coated hip joints in the past [7]. Testing by Lappalainen et al. [39], and to a lesser extent Dowling et al. [40] and Oñate et al. [50] tested over 15 million, 6 million and 5 million cycles on joint simulators respectively(Lappalainen estimated 1 million cycles to be equivalent to 1 year in use). These long term tests showed good results in wear reduction and life of the coating. Many of these failures may have been prevented by the use of interlayers, increasing the adhesion to the surface and reducing the residual stress in the coating. More modern coatings use gradiated coatings, with different levels of $\mathrm{sp}^{2}$ and $\mathrm{sp}^{3}$ in layers in the coating, and interlayers of other elements between the substrate and coating (such as $\mathrm{Cu}, \mathrm{Si}_{3} \mathrm{~N}_{4}, \mathrm{Cr}$ and $\mathrm{CrN}$ ) $[13,51,52]$ to attempt to diminish these issues.

However, the results to date are conflicting, both Lappalainen $[39,44]$ and Oñate [50] mention the use of an interlayer, but provide no information about what type. Dowling [40] specifically mentions no interlayer being used, but gets a better wear reduction, over a longer testing period than those of Oñate.

However, the advancements in deposition over time (more complex interlayers etc) do not explain the differences in results in some of the other testing. Some of the earliest tests (Dowling [40]and Lapalainen et al. [44]) provide some of the most positive results compared to the later tests (Fisher et al. [42]). However, as Fisher does not mention the coating used, or any interlayers it could be possible that none were used, which could show that the advancements in coatings are improving the performance of the coating.

One of the most common suggestions for failure is that wear debris can act as an abrasive in the contact, localising stress which can cause plastic yielding in the surface under the thin coating. As the explant study (Taeger et al. [38]) also suggests that the wear debris is the likely cause of premature biological failure, the main aim for improvement in the coatings is to make them more resistant to wear (resulting in less debris) or to make the debris less harmful to the body.

The relevancy of the in vitro tests compared to that of an in vivo test is difficult, as no true in vitro test can mirror the conditions of the body accurately. Factors like micro-seperation (small separation between the cup and ball in the implant), transient contacts (spikes of load that can occur on changing activity) and an unpredictable walking loading cycle in a real implant are not predictable in a simulator, nor is the body's natural reaction to it. However a hip simulator is currently the most accurate testing that can be done outside of the body.

\subsection{Further work}

It is clear that DLC's could be a viable candidate for coating onto implants. However, further work needs to be done on them before they can be put forward for use again.

Firstly the data needs to be repeatable. With many different tests, using such a wide range of testing conditions and coatings giving as much variance in the results as they are, tests need to be repeated to derive the accurate performance of the coating. Future testing must use a purpose designed coating in a variety of different testing conditions, or use a constant regulated test on a variety of coatings.

No papers have evaluated the tribo-corrosion performance of the samples during wear testing, on either a pin on disc or a hip simulator, which would need to be done to accurately inform on how the samples react in the body.

\section{Conclusions}

The following conclusions are based upon a review of the published open literature on diamond like carbon (DLC) coated biomedical grade metals:

1. Findings from clinical and laboratory based tests on the suitability of DLC coating materials for joint replacement bearing surfaces remains inconclusive. Some results indicate DLC coated materials to be promising whilst others suggest they are unsuitable.

2. Of the positive results, hip joint simulator tests have indicated that the wear volume of UHMWPE acatabular cups is reduced (up to 14 times) when the opposing metallic femoral head is coated with DLC coating materials based on ta-C (tetrahedral carbon). Such benefit is greatest when conducting tests in bovine serum solutions.

3. Interlayers provide benefits to the performance of the coatings in both pin on disc and hip simulator testing, when contrasted to a DLC system without an interlayer. 
4. More standardised testing would be required for comparisons and conclusions to be more practical. In addition full disclosure on all conditions (DLC composition, interlayer, testing loading etc) would be required in future to allow comparable results.

\section{References}

1] Registry NJ. NJR StatsOnline. NJR 2011.

[2] Ebramzadeh E, Campbell PA, Takamura KM, Lu Z, Sangiorgio SN, Kalma JJ, et al. Failure modes of 433 metal-on-metal hip implants: how, why, and wear. Orthopedic Clinics of North America 2011;42:241-50.

[3] Hummer Iii CD, Rothman RH, Hozack WJ. Catastrophic failure of modular Zirconia-Ceramic femoral head components after total hip arthroplasty. Journal of Arthroplasty 1995;10:848-50.

[4] Fisher J, Hu X, Tipper J, Stewart TD, Williams S, Stone M, et al. An in vitro study of the reduction in wear of metal-on-metal hip prostheses using surface-engineered femoral heads. Journal of Engineering in Medicine 2002:216.

[5] Clark GCF, Williams DF. The effects of proteins on metallic corrosion. Journal of Biomedical Materials Research 1982;16:125-34.

[6] Dearnaley G, Arps JH. Biomedical applications of diamond-like carbon (DLC) coatings: a review. Surface and Coatings Technology 2005;200:2518-24.

[7] Hauert R. A review of modified DLC coatings for biological applications. Diamond and Related Materials 2003;12:583-9.

[8] Cui FZ, Li DJ. A review of investigations on biocompatibility of diamond-like carbon and carbon nitride films. Surface and Coatings Technology 2000;131:481-7.

[9] Erdemir A, Donnet C. Tribology of diamond-like carbon films: recent progress and future prospects; 2006. p. 39.

[10] Dearnley PA, Neville A, Turner S, Scheibe H, Tietema R, Tap R, et al. Coatings tribology drivers for high density plasma technologies. Surface Engineering 2010:26.

[11] Ray S, Middya AR, Barua AK. Diamond like carbon films prepared by photochemical vapor deposition. Japanese Journal of Applied Physics 1993;32:1559-61.

[12] Robertson J. Diamond Like amorphous carbon. Materials and Science Engineering 2002:37.

[13] Nakazawa H, Mikami T, Enta Y, Suemitsu M, Mashita M. Structure, chemical bonding and these thermal stabilities of diamond-like carbon (DLC) films by rf magnetron sputtering. Japanese Journal of Applied Physics 2003:676-9.

[14] Bremond F, Fournier P, Platon F. Test temperature effect on the tribological behavior of DLC-coated 100C6-steel couples in dry friction. Wear 2003:774-83.

[15] Nakazawa H, Katoh S, Asai Y, Mashita M. Effects of substrate bias voltage on structural, mechanical and tribological properties of diamond like carbon films prepared by plasma-enhanced chemical vapor deposition using methane and argon gases. Japanese Journal of Applied Physics 2008;47:231-6.

[16] Erdemir A, Liu Y, Meletis EI. Influence of environmental parameters; 1997.

[17] Voevodin AA, Phelps AW, Zabinski JS, Donley MS. Friction induced phase transformation of pulsed laser deposited diamond-like carbon. Diamond and Related Materials 1996;5:1264-9.

[18] Fountzoulas CG, Kattamis TZ, Demaree JD, Hirvonen JK. Silicon-containing diamond like-carbon coatings formed by ion beam assisted deposition (IBAD): processing and properties of a new category of hard, wear resistant thin films. In: Proceedings of the Third International Conference on applications of diamond films and related materials; 1995. p. 907.

[19] Dearnley PA, Aldrich-Smith G. Corrosion-wear mechanisms of hard coated austenitic $316 \mathrm{~L}$ stainless steels. Wear 2004:256.

[20] X-Z. Ding, Tay BK, Lau SP, Zhang P, Zeng XT. Structural and mechanical properties of Ti-containing diamond-like carbon films deposited by filtered cathodic vacuum arc. Thin Solid Films 2002;408:183-7.

[21] Kwok SCH, Zhang W, Wan GJ, McKenzie DR, Bilek MMM, Chu PK. Hemocompatibility and anti-bacterial properties of silver doped diamond-like carbon prepared by pulsed filtered cathodic vacuum arc deposition. Diamond and Related Materials 2007;16:1353-60.

[22] Choi HW, Dauskardt RH, Lee SC, Lee KR, Oh KH. Characteristic of silver doped DLC films on surface properties and protein adsorption. Diamond and Related Materials 2008;17:252-7.

[23] Kim YK, Kitaoka M, Hayashi K, Kim CH, Côté GL. A synergistic reaction mechanism of a cycloalternan-forming enzyme and a D-glucosyltransferase for the production of cycloalternan in Bacillus sp. NRRL B-21195. Carbohydrate Research 2003;338:2213-20.

[24] McLaughlin JA, Meenan B, Maguire P, Jamieson N. Properties of diamond like carbon thin film coatings on stainless steel medical guidewires. Diamond and Related Materials 1996;5:486-91.

[25] Meunier C, Stauffer Y, Daglar A, Chai F, Mikhailov S, Hildebrand HF. Comparison of hydrogenated and unhydrogenated carbon films obtained by FCVA onto Ti-6Al-4V: structure, hardness and biocompatibility study. Surface and Coatings Technology 2006;200:6346-9.
[26] Alakoski E, Tiainen VM, Soininen A, Konttinen Y. Load-bearing biomedical applications of diamond-like carbon coatings-current status. The Open Orthopaedics Journal 2008:2.

[27] Tiainen VM. Amorphous carbon as a bio-mechanical coating-mechanical properties and biological applications. Diamond and Related Materials 2001:10:153-60.

[28] Sondi I, Salopek-Sondi B. Silver nanoparticles as antimicrobial agent: a case study on $E$. coli as a model for Gram-negative bacteria. Journal of Colloid and Interface Science 2004;275:177-82.

[29] Kim JS, Kuk E, Yu KN, Kim JH, Park SJ, Lee HJ, et al. Antimicrobial effects of silver nanoparticles. Nanomedicine: Nanotechnology, Biology and Medicine 2007;3:95-101.

[30] Chekan NM, Beliauski NM, Akulich VV, Pozdniak LV, Sergeeva EK, Chernov AN, et al. Biological activity of silver-doped DLC films. Diamond and Related Materials 2009;18:1006-9.

[31] Choi HW, Choi JH, Lee KR, Ahn JP, Oh KH. Structure and mechanical properties of Ag-incorporated DLC films prepared by a hybrid ion beam deposition system. Thin Solid Films 2007;516:248-51.

[32] Allen M, Myer B, Rushton N. In vitro and in vivo investigations into the biocompatability of diamond like carbon coatings for orthopedic applications. Journal of Biomedical Materials Research 2001:58.

[33] Ali SS, Hardt JI, Quick KL, Sook Kim-Han J, Erlanger BF, Huang TT, et al. A biologically effective fullerene (C60) derivative with superoxide dismutase mimetic properties. Free Radical Biology and Medicine 2004;37:1191-202.

[34] Marciano FR, Bonetti LF, Mangolin JF, Da-Silva NS, Corat EJ, Trava-Airoldi VJ. Investigation into the antibacterial property and bacterial adhesion of diamond-like carbon films. Vacuum 2011;85:662-6.

[35] Marciano FR, Bonetti LF, Santos LV, Da-Silva NS, Corat EJ, Trava-Airoldi VJ. Antibacterial activity of DLC and Ag-DLC films produced by PECVD technique. Diamond and Related Materials 2009;18:1010-4.

[36] Dibrov P, Dzioba J, Goskin K, Hase C. Chemiosmotic mechanism of antimicrobial activity of $\mathrm{Ag}+$ in Vibrio cholerae. Antimicrobial agents and Chemotherapy 2002;46:2668-70.

[37] Marnett LJ. Lipid peroxidation-DNA damage by malondialdehyde. Mutation Research/Fundamental and Molecular Mechanisms of Mutagenesis 1999 83-95.

[38] Taeger T, Podleska LE, Schmidt B, Ziegler M, Nast-Kolb D. Comparison of diamond like carbon and alumina oxide articulating with polyethylene in total hip arthoplasty. Materialwissenschaft und Werkstofftechnik 2003:34.

[39] Lappalainen R, Selenius M, Anttila A, Konttinen Y, Santavirta S. Reduction of wear in total hip replacement prostheses by amorphous diamond coatings. Journal of Biomedical Materials Research 2002:66B.

[40] Dowling DP, Kola PV, Donnelly K, Kelly TC, Brumitt K, Lloyd L, et al. Evaluation of diamond-like carbon-coated orthopaedic implants. Diamond and Related Materials 1997;6:390-3.

[41] Affatato S, Frigo M, Toni A. An in vitro investigation of diamond like carbon as a femoral head coating. Journal of Biomedical Materials Research 2000;53:221-6.

[42] Fisher J, Hu X, Stewart TD, Williams S, Tipper J, Ingham E, et al. Wear of surface engineered metal-on-metal hip prostheses. Journal of Materials Science: Materials in Medicine 2004:15.

[43] Saikko V, Ahlroos T, Calonius O, Keränen J. Wear simulation of total hip prostheses with polyethylene against $\mathrm{Co}-\mathrm{Cr}$, alumina and diamond-like carbon. Biomaterials 2001;22:1507-14.

[44] Lappalainen R, Heinonen H, Anttila A, Santavirta S. Some relevant issues related to the use of amorphous diamond coatings for medical applications. Diamond and Related Materials 1998;7:482-5.

[45] Shi B, Ajayi OO, Fenske G, Erdemir A, Liang H. Tribological performance of some alternative bearing materials for artificial joints. Wear 2003;255:1015-21.

[46] Xu T, Pruitt L. Diamond Like Carbon coatings for orthopaedic applications; An evaluation of tribological performance. Journal of Materials Science: Materials in Medicine 1999:10.

[47] Sheeja D, Tay BK, Lau SP, Nung LN. Tribological characterisation of diamondlike carbon coatings on $\mathrm{Co}-\mathrm{Cr}$-Mo alloy for orthopaedic applications. Surface and Coatings Technology 2001;146-147:410-6.

[48] Dong H, Shi W, Bell T. Potential of improving tribological performance of UHMWPE by engineering the Ti-6Al-4V counterfaces. Wear 1999;225 229:146-53.

[49] Thorwarth G, Falub CV, Müller U, Weisse B, Voisard C, Tobler M, et al Tribological behavior of DLC-coated articulating joint implants. Acta Biomaterialia 2010;6:2335-41.

[50] Oñate JI, Comin M, Braceras I, Garcia A, Viviente JL, Brizuela M, et al. Wear reduction effect on ultra-high-molecular-weight polyethylene by application of hard coatings and ion implantation on cobalt chromium alloy, as measured in a knee wear simulation machine. Surface and Coatings Technology 2001;142-144:1056-62.

[51] Gomes JR, Camargo SS, Simao RA, Carrapichano JM, Achete CA, Silva RF. Tribological properties of silicon nitride ceramic coated with DLC and DLC-Si against 316 L stainless steel. Vacuum 2007;81:1448-52.

[52] Puchi-Cabrera ES, Staia MH, Ochoa-Pérez EA, Teer DG, Santana-Méndez YY, La Barbera-Sosa JG, et al. Fatigue behavior of a $316 \mathrm{~L}$ stainless steel coated with a DLC film deposited by PVD magnetron sputter ion plating. Materials Science and Engineering: A 2010;527:498-508. 